\title{
ANÁLISE DAS CONDIÇÕES DE TRABALHO DA POLÍCIA RODOVIÁRIA FEDERAL E SUA INFLUÊNCIA NA CAPACIDADE PARA TRABALHAR
}

\section{WORK CONDITIONS ANALYSIS OF THE FEDERAL HIGHWAY POLICE AND THE INFLUENCE IN WORK ABILITY}

\begin{abstract}
Leonardo Tomazi Gaspary ${ }^{1}$; Lisiane Priscila Roldão Selau ${ }^{2}$; Fernando Gonçalves Amaral ${ }^{3}$
${ }^{1}$ Federal University of Rio Grande do Sul - UFRGS - Porto Alegre - Brasil leonardogaspary@yahoo.com.br ${ }^{2}$ Federal University of Rio Grande do Sul - UFRGS - Porto Alegre - Brasil lisianeselau@producao.ufrgs.br ${ }^{3}$ Federal University of Rio Grande do Sul - UFRGS - Porto Alegre - Brasil amaral@producao.ufrgs.br
\end{abstract}

\begin{abstract}
Resumo
A motivação e a satisfação dos trabalhadores, com relação às condições de trabalho, são alguns dos aspectos que estão em primeiro plano nas discussões acerca da produtividade e desempenho das organizações. A compreensão das condições de trabalho torna-se, então, importante para evitar o envelhecimento funcional e a diminuição da capacidade para o trabalho. Neste contexto, o estudo objetivou analisar as condições de trabalho dos servidores da Polícia Rodoviária Federal em Porto Alegre e Região Metropolitana, procurando identificar fatores capazes de influenciar a capacidade para trabalhar. A metodologia utilizada compreendeu a aplicação de questionários para avaliar a satisfação com o trabalho e o Índice de Capacidade para o Trabalho (ICT). Isto permitiu a elaboração de um diagnóstico preliminar sobre as condições de trabalho dos policiais rodoviários federais. Os resultados indicaram que a autonomia, as possibilidades de promoção e $o$ tempo de serviço são os fatores que mais interferem no resultado do índice calculado.
\end{abstract}

Palavras-chave: polícia rodoviária, índice de capacidade para o trabalho, envelhecimento funcional.

\section{Introdução}

As questões relacionadas aos recursos humanos das empresas como a insatisfação, a desmotivação e o desconforto nos locais de trabalho influem diretamente no desempenho e produtividade das organizações. Neste sentido, deve-se buscar então medidas de prevenção para amenizar tais aspectos.

Durante toda a fase produtiva, o corpo humano sofre alterações decorrentes dos esforços aos quais é submetido. É válido ressaltar que, além destas alterações, todas as funções do corpo humano ainda são fortemente influenciadas pelo processo do envelhecimento. 
De acordo com Meirelles (1997), o envelhecimento não é um processo unilateral, mas a soma de vários processos, os quais envolvem aspectos biopsicossociais, em que é importante o ambiente de trabalho do indivíduo, bem como seu ambiente familiar e social, suas atividades e hábitos diários e seu relacionamento com as pessoas.

Pohjonen (1991) considera que, além das condições físicas do ambiente de trabalho, a satisfação no trabalho com aspectos biopsicossociais também pode afetar a capacidade do trabalhador. A capacidade para o trabalho é uma pré-condição para uma satisfatória condição geral de saúde. Porém, considerando a importância do trabalho para o ser humano e a carência de estudos sobre as associações entre satisfação e capacidade para o trabalho, fica evidente que esta é uma área de investigação. Seu desenvolvimento está no sentido de verificar como as medidas que visam o implemento da satisfação podem contribuir para a preservação ou ampliação da capacidade para o trabalho.

Neste contexto, a satisfação no trabalho encontra-se relacionada com a saúde do trabalhador, indicando que maiores níveis de satisfação estão associados significativamente com melhores condições de saúde do trabalhador. Da mesma forma, a satisfação no trabalho aumenta a motivação e a produtividade do trabalhador (MARTINEZ, 2002).

Nahas (2001) sugere outro fator impactante na produtividade e desempenho das organizações, a Qualidade de Vida no Trabalho (QVT), que pode ser alcançada através de diversos fatores: moradia, assistência médica, condições de trabalho e remuneração, acesso à educação, opções de lazer, integração com o meio ambiente e segurança. O autor também relaciona aspectos individuais como a hereditariedade, estilo de vida, hábitos alimentares, controle do estresse, atividade física habitual, não utilização de fumo, álcool e drogas.

Desse modo, todas as organizações em geral, inclusive as públicas, devem estar atentas ao desempenho de seus trabalhadores, seu processo de envelhecimento, sua satisfação e sua motivação no trabalho. Caso contrário, estarão fadadas a uma significativa queda de desempenho global, já que são os trabalhadores os verdadeiros responsáveis pelo sucesso das instituições. Assim, é necessário um constante acompanhamento preventivo para que a capacidade de trabalho dos servidores possa ser avaliada para que se mantenha em um bom patamar.

A partir dessas considerações, justifica-se a necessidade de se fazer uma abordagem prática sobre o grau de satisfação dos trabalhadores. A empresa só poderá atingir os seus objetivos organizacionais através da participação de seus colaboradores. Além disso, uma organização essencialmente prestadora de serviços deve monitorar permanentemente o grau de satisfação e capacidade para o trabalho das pessoas que, diariamente, prestam serviços à comunidade (SANTOS, 2004). 
O objetivo geral desta pesquisa é avaliar a capacidade de trabalho e o grau de motivação e satisfação dos servidores da área operacional da Polícia Rodoviária Federal (PRF) em Porto Alegre e Região Metropolitana. As constatações obtidas poderão permitir estabelecer os objetivos específicos do estudo: (i) analisar a influência do envelhecimento na capacidade para trabalhar dos servidores, utilizando o método do Índice de Capacidade para o Trabalho (ICT); (ii) observar o grau de satisfação dos funcionários em geral; (iii) obter um diagnóstico preliminar sobre as condições de trabalho desses servidores, com indicações de melhoria e estudos futuros.

\section{Fundamentação Teórica}

A fundamentação teórica baseou-se nos resultados de uma revisão da literatura, buscando as definições para fundamentar o desenvolvimento do presente estudo. Primeiramente, foi analisada a situação atual da PRF, identificando as condições de trabalho dos policiais rodoviários e, após, foi apresentada a revisão de literatura sobre o envelhecimento funcional e o Índice de Capacidade para o Trabalho.

\subsection{A Polícia Rodoviária Federal}

A Polícia Rodoviária Federal (PRF) foi criada em 24 de julho de 1928, através do Decreto $\mathrm{n}^{\mathrm{o}}$ 18.323, com a denominação inicial de 'Polícia das Estradas'. Conforme Santos (2004), a Polícia Rodoviária Federal, sendo integrante da estrutura do Ministério da Justiça, tem como competência desenvolver as seguintes atividades essenciais no âmbito das rodovias federais:

- realizar o policiamento ostensivo, executando operações relacionadas com a segurança pública, com o objetivo de preservar a ordem, a incolumidade das pessoas, o patrimônio da União e o de terceiros;

- exercer poder de autoridade de trânsito, cumprindo e fazendo cumprir a legislação e demais normas pertinentes;

- executar serviços de prevenção e atendimento de acidentes, socorrendo vítimas acidentadas nas rodovias federais;

- assegurar a livre circulação, promovendo intervenções de construções, obras e instalações não autorizadas às margens das rodovias;

- realizar perícia, levantamento de locais, boletins de ocorrência, investigações, testes de dosagem alcoólica e outros procedimentos estabelecidos em lei. 
Após 80 anos, apresenta ainda alguns obstáculos a serem vencidos em sua atuação: como motivar seu quadro operacional para melhor cumprir sua missão constitucional? Como evitar a queda de produtividade de seus trabalhadores? Assim, considerando a estrutura organizacional, com um efetivo digno de grandes corporações (cerca de oito mil policiais em todo o Brasil) o Departamento de Polícia Rodoviária Federal iniciou, nos últimos anos, a implantação de uma visão moderna de gestão (DPRF, 2004). Esta procurando atender às demandas crescentes da sociedade, através da capacitação dos servidores, da modernização tecnológica, da participação em Conselhos de Segurança, bem como em operações integradas com outros órgãos de Segurança Pública. Porém, com todas as mudanças no ambiente organizacional, observa-se que o Policial Rodoviário Federal carece ainda de medidas de apoio que o acompanhem em sua vida profissional dando-lhe mais suporte.

Neste contexto, a Polícia Rodoviária Federal no Estado do Rio Grande do Sul trabalha com reduzido efetivo, situação esta que afeta diretamente a produtividade e o atendimento de suas funções constitucionais. A defasagem de efetivo vem se evidenciando continuamente, principalmente porque um grande número de servidores ativos está alcançando o tempo de serviço necessário para aposentadoria, reduzindo significativa e constantemente o quadro de Policiais Rodoviários Federais ativos da Instituição (DPRF, 2004).

Silva (2003) informa que, com a crescente gama de competências, não só institucionais, mas também com os convênios firmados, as ações da PRF têm se tornado cada vez mais estafantes e estressantes. Acrescido a estas competências está o constante aumento da criminalidade, que tem exigido o alerta permanente do policial, principalmente no trabalho noturno.

Em uma pesquisa realizada por Santos (2004), foram observados os principais fatores que contribuem para a motivação ou desmotivação dos Policiais Rodoviários Federais: na questão de condições de trabalho e conforto, $39,53 \%$ dos entrevistados a consideraram regular, 18,60\% ruim e $13,95 \%$ péssima, mesmo assim os policiais sentem-se motivados para o trabalho (79,55\%). Observou-se também que $31,43 \%$ dos policiais responderam que a afinidade, seguida da estabilidade e do salário (ambos com 22,86\%) são os principais fatores de sua motivação. O autor indica que as atribuições do cargo de Policial Rodoviário Federal requerem muita atenção, capacitação profissional e muita saúde de seus ocupantes. Além da distância entre a casa e o trabalho e das condições insalubres, decorrentes da própria natureza do cargo, existe o alto risco de morte também inerente à função policial. Estas três características, categorizadas como intrínsecas à profissão, não esgotam todas as possibilidades de fatores que podem estressar o PRF ou desestabilizá-lo emocionalmente. Há ainda fatores extrínsecos, como ser arrimo de mais de uma família, dependência química, insônia, além de familiares com problemas de saúde, etc., que contribuem para aumentar as preocupações do servidor, afetando o seu estado de saúde. 


\subsection{Envelhecimento Funcional}

$\mathrm{Na}$ questão do envelhecimento, é natural observar que os policiais envelhecem no trabalho (devido à longa permanência na instituição), como também envelhecem pelo trabalho (devido aos impactos gerados pelo exercício da função). Neste contexto, convém salientar que o impacto do envelhecimento é variável nas diferentes idades, segundo os ofícios exercidos (MARQUIÉ, 1995). Para Ilmarinen (1993), o envelhecimento é freqüentemente combinado com declínio da capacidade funcional. Por outro lado, exigências do trabalho não diminuem com a idade; podem até aumentar. Com mais experiência, as exigências do trabalho, pelo menos em atividades com grande exigência mental, tendem a aumentar com a idade.

Segundo Bellusci (2002), o envelhecimento está associado a uma progressiva deterioração da saúde e do aumento na suscetibilidade às doenças. É de grande importância a compreensão deste processo e suas relações com a capacidade funcional, a fim de serem adaptadas as exigências do trabalho aos servidores que envelhecem, evitando-se assim o afastamento precoce da vida ativa de trabalho. O envelhecimento funcional não está necessariamente relacionado ao envelhecimento cronológico. Depende das condições de vida e trabalho, além das características individuais e estilos de vida adotados.

O envelhecimento funcional (que freqüentemente se faz notar antes do envelhecimento cronológico) ocorre quando um indivíduo, em função da deterioração da sua saúde física e mental, passa a depender de outros para o cumprimento de suas necessidades básicas ou de tarefas habituais (PASCHOAL, 1996). O envelhecimento funcional é mais valorizado em nossa cultura que o envelhecimento cronológico, e poucos problemas merecem tanto a atenção do homem como os problemas do envelhecimento e da capacidade funcional. O envelhecimento cronológico é caracterizado quando o indivíduo começa a ter lapsos de memória, dificuldade de aprendizado e falha de atenção, orientação e concentração, comparativamente com sua capacidade intelectual anterior; enfim, quando apresenta modificações desfavoráveis em seu sistema cognitivo (LEME, 1996).

Conforme aumenta a idade dos indivíduos, ocorre uma redução sensível no percentual dos ocupados absorvidos pelas empresas privadas. Neste âmbito, os problemas enfrentados pelos trabalhadores, em razão das mudanças estruturais, da evolução conjuntural e da situação de desemprego, são mais graves para os trabalhadores com mais de 40 anos (MARÍN; IGUTI, 1997). Assim, o problema mais urgente, no que se refere à força de trabalho, diz respeito a como manter ativos estes trabalhadores até a sua aposentadoria. 
Já em instituições públicas, isso não ocorre freqüentemente: o servidor tem estabilidade e pode realizar seu trabalho com certa comodidade. Tal fato pode ser prejudicial às organizações públicas, visto que alguns funcionários podem estagnar seu processo de aprendizagem e crescimento na empresa. Por outro lado, ser estável é uma grande vantagem para o servidor que envelhece, pois é notória a dificuldade de se obter emprego quando ultrapassa os 45 anos (SOUZA, 2003).

No âmbito do setor público, Bellusci (2002) observou que o trabalho realizado no Judiciário Federal em São Paulo traz importante comprometimento da saúde e envelhecimento precoce devido: à dificuldade de relacionamento interpessoal, à falta de perspectiva de ascensão profissional, às exigências excessivas da quantidade e qualidade do trabalho, ao uso de premiação de forma injusta e também fatores relacionados à falta de controle no trabalho, entre outros fatores. Estes indicadores expressam a necessidade de intensificar ações para proteger as populações de trabalhadores em meio ao setor público. Assim, com o gradual envelhecimento das populações destes trabalhadores, torna-se ainda mais importante detectar alterações na saúde para evitar o envelhecimento funcional precoce.

\section{3 Índice de Capacidade para o Trabalho}

A capacidade para o trabalho é uma das bases do bem-estar para todos os indivíduos, sendo que sua avaliação deve ser baseada em dados obtidos de várias fontes. Desta forma, tanto o conceito que o trabalhador tem da sua capacidade para o trabalho quanto dos especialistas são importantes para avaliar a capacidade para o trabalho. Em conjunto, estas avaliações fornecem uma visão melhor da capacidade para o trabalho, verificada através de um índice denominado Índice de Capacidade para o Trabalho - ICT (TUOMI et al., 1997a). De acordo com os autores, essas avaliações são convergentes com resultados de exames clínicos e são consideradas como de qualidade.

Em amplos estudos de acompanhamento do Instituto de Saúde Ocupacional da Finlândia, o Índice de Capacidade para o Trabalho tem prognosticado, com confiabilidade, mudanças na capacidade para o trabalho em diferentes grupos ocupacionais. O objetivo principal destes estudos foi a redução de aposentadorias por incapacidade e a manutenção da capacidade para o trabalho de trabalhadores ativos. Em função destas pesquisas foi desenvolvido um instrumento para medir a capacidade de trabalho baseado na auto-avaliação dos trabalhadores de sua capacidade para o trabalho atual e futura; considerando o número de doenças, percepção de suas condições físicas e mentais frente aos desafios das tarefas e sintomas de bem-estar psicológico (TUOMI et al., 1997b). 
O Índice de Capacidade para o Trabalho segundo Ilmarinen (1995, p.5), é definido como: “quão bem está, ou estará, um (a) trabalhador (a) no momento atual ou num futuro próximo, e quão bem ele ou ela pode executar seu trabalho, em função das exigências, de seu estado de saúde e capacidades físicas e mentais". Deve-se ressaltar que a capacidade para o trabalho não se mantém satisfatória permanentemente, a não ser que o profissional invista nele mesmo, influenciando alguns fatores modificáveis, como atividade física diária aliada a melhorias no ambiente de trabalho (BOLDORI, 2002).

Para Zeni (2004), com o auxílio do índice pode-se, num estágio precoce, identificar trabalhadores e ambientes de trabalho que necessitam de medidas de apoio. Essas medidas ou avaliações adicionais da capacidade para o trabalho são necessárias para aqueles em que o Índice de Capacidade para o Trabalho é baixo (pontuação abaixo de 27). Para aqueles em que o ICT é moderado (pontuação entre 28 e 36) ou bom (pontuação entre 37 a 43), são recomendadas medidas para melhorá-lo. Trabalhadores com ótimo ICT (pontuação entre 44 e 49) devem, quando necessário, receber instruções sobre como mantê-lo. De acordo com o escore, é feita a classificação como mostra a Figura 1.

Figura 1 - Nível de capacidade para o trabalho

\begin{tabular}{|c|c|c|}
\hline Pontos & Capacidade para o trabalho & Objetivos das medidas \\
\hline $7-27$ & Baixa & Restaurar a capacidade para o trabalho \\
\hline $28-36$ & Moderada & Melhorar a capacidade para o trabalho \\
\hline $37-43$ & Boa & Melhorar a capacidade para o trabalho \\
\hline $44-49$ & Ótima & Manter a capacidade para o trabalho \\
\hline
\end{tabular}

Fonte: Tuomi et al. (1997a, p. 6).

De acordo com o identificado nos estudos relativos aos policiais rodoviários, considera-se importante identificar o estado das condições de trabalho em que se encontram estes sujeitos; bem como, os fatores inerentes ao trabalho capazes de influenciar sua própria capacidade para o trabalho. Assim, a metodologia que segue procura avaliar tais condições de trabalho entre os policiais rodoviários federais.

\section{Método de Pesquisa}

A pesquisa foi realizada no âmbito da Superintendência do Rio Grande do Sul, com os trabalhadores que atuam em Porto Alegre e na Região Metropolitana, mais precisamente na $1^{\text {a }}$ Delegacia PRF Regional, incluindo os postos das cidades de Gravataí, Porto Alegre e São Leopoldo. Os sujeitos participantes eram todos voluntários, sendo o total de entrevistados de 43 policiais, representando 59\% do total de 73 policiais lotados na Delegacia. Os trechos em que os 
policiais realizam seu trabalho são os de tráfego mais intenso do Estado, abrangendo as cidades de Cachoeirinha, Gravataí, Glorinha (BR 290), Canoas, Esteio, Novo Hamburgo, São Leopoldo, Sapucaia do Sul (BR 116) e Porto Alegre (BRs 116 e 290). Para investigar a capacidade para o trabalho e o grau de satisfação destes policiais foram aplicados dois questionários distintos.

Para a avaliação da capacidade para o trabalho, foi aplicado o questionário denominado Índice de Capacidade para o Trabalho, desenvolvido pelo Instituto de Saúde Ocupacional da Finlândia (TUOMI et al., 1997a). O questionário de avaliação de capacidade para o trabalho é formado por sete itens, cada um avaliado por uma ou mais questões, as quais consideraram: as demandas físicas e mentais de trabalho, a capacidade para o trabalho atual comparada com a melhor de toda a vida, capacidade para o trabalho em relação às exigências deste, número atual de doenças diagnosticadas por médico, perda estimada para o trabalho devido às doenças, faltas ao trabalho por doenças nos últimos 12 meses, prognóstico próprio sobre a capacidade para o trabalho daqui a dois anos e recursos mentais. Cada item recebeu pontos de acordo com uma escala, cujo somatório resulta em escores de 7 a 49 pontos. Esse número retrata o próprio conceito do trabalhador sobre sua capacidade para o trabalho. Como esse questionário é respondido pelo próprio indivíduo, cada participante recebeu instruções quanto ao preenchimento do instrumento.

O segundo questionário foi construído com elementos definidos a partir de observação ergonômica, dividindo-se em duas partes. A primeira parte do questionário investigou o grau de satisfação dos servidores em relação às condições de trabalho nos seguintes aspectos: ambiente de trabalho; questões psicossociais e organizacionais; características do trabalho (físicas, mentais e sociais). A escala de resposta neste segundo instrumento consistia de uma linha contínua de 15 centímetros com âncoras nas extremidades indicando as medidas extremas de 'muito insatisfeito' ou 'pouco' à esquerda e 'muito satisfeito' ou 'muito' à direita. O respondente deve marcar ao longo da linha o ponto que corresponde a seus sentimentos sobre a questão formulada. Desta forma, o valor máximo alcançado pela resposta é 15 e o mínimo 0 . O estilo da escala foi escolhido em função da facilidade de preenchimento, considerando-se o número de 29 questões. Além disso, a escala em linha sem marcações permite ao respondente exprimir livremente e de forma gráfica a sua percepção a respeito da questão formulada. Na segunda parte, foram explorados os dados pessoais e de estilo de vida para caracterizar o perfil demográfico da população estudada, como por exemplo: características pessoais, dados funcionais, turnos de trabalho, escalas de serviço, características do sono e horários de dormir. Nesta segunda parte foram elaboradas oito questões de múltipla escolha.

Com o intuito de entender o comportamento de cada uma das variáveis estudadas, e analisar os relacionamentos entre si, a análise estatística empregada foi tendo seu nível de agregação aumentado. Partiu-se da análise univariada para avaliar os resultados individuais das características, através de tratamento percentual e cálculo de medidas descritivas como média e desvio padrão. Em 
seguida, utilizou-se a análise bivariada com o cruzamento de variáveis duas a duas, para, com isso, verificar a existência de associações significativas. Com a análise multivariada, tentou-se capturar o relacionamento conjunto das variáveis e sua interferência no resultado do Índice de Capacidade para o Trabalho.

\section{Resultados}

\subsection{Análise Univariada}

$\mathrm{Na}$ amostra estudada verificou-se um perfil predominante de homens (93\%), casados $(58,1 \%)$ e com nível superior incompleto $(62,8 \%)$. Observou-se que a idade média dos funcionários foi de 31,9 anos com desvio padrão de 5,98 e que o policial de idade mais avançada tinha 43 anos e o mais novo, 22. Avaliando o tempo de serviço, verificou-se que o tempo médio na organização foi de 5,4 anos com desvio padrão de 5,2. Já o tempo de serviço mínimo foi de quatro meses (policiais oriundos da última turma do concurso mais recente) e o máximo, 19 anos.

As características de qualidade do sono dos servidores, a auto-avaliação do trabalho em turnos (prejudicial ou não às atividades) e a satisfação em relação à escala de serviço também foram avaliadas. Como o trabalho em turnos exige que os policiais fiquem acordados durante seus plantões, é possível que muitos não consigam dormir cedo, devido à alteração do ritmo circadiano. Em relação à quantidade de horas de sono, $76,7 \%$ dos entrevistados dormem menos de 8 horas diárias, que seria o tempo de descanso ideal na opinião de muitos especialistas. Mesmo considerando as variações interindividuais, observou-se um grande número de servidores que não atingem o tempo de descanso considerado ideal, o que também pode ser um reflexo do trabalho em turnos.

A auto-avaliação do trabalho em turnos mostrou que $65,1 \%$ dos policiais acreditam que ele não afeta o seu desempenho profissional, ao passo que 34,9\% vêem prejuízos decorrentes deste tipo de organização do trabalho. Como a escala de serviço é de 24 horas de trabalho por 72 horas de descanso para a maior parte da amostra $(48,8 \%)$, o resultado pode ter sido influenciado, visto que essa escala é considerada uma das vantagens de se trabalhar na PRF, devido à folga de três dias consecutivos. A escala de serviço foi considerada ótima ou boa para 58,1\% dos sujeitos.

Pelos dados explicitados na Tabela 1 -, percebe-se a preocupação dos servidores com suas condições de trabalho, já que apenas o item distância do local de trabalho teve satisfação média maior de 10. A insatisfação é maior para a questão dos serviços de manutenção em viaturas e nos postos com a média assumindo o valor 4,97. Os itens infra-estrutura, segurança, quantidade e 
conservação dos equipamentos e material básico de almoxarifado, como tinta para impressão e formulários de uso operacional, foram todos considerados insatisfatórios, com médias bastante baixas. A última questão é relativa à satisfação geral do ambiente físico do trabalho, como conforto, iluminação, condições térmicas, ruído, fumaça e poeira, refletindo o descontentamento dos servidores com a falta de medidas que evitem os efeitos prejudiciais da natureza do serviço, apresentando uma média de 5,72 e desvio padrão de 2,89.

Tabela 1 - Satisfação em relação ao local de trabalho

\begin{tabular}{l|c|c|c|c}
\hline \multicolumn{1}{c|}{ Item } & Média & $\begin{array}{c}\text { Desvio } \\
\text { Padrão }\end{array}$ & Mínimo & Máximo \\
\hline Infra-estrutura & 7,50 & 2,31 & 2,10 & 11,90 \\
\hline Segurança à noite & 7,12 & 2,56 & 2,83 & 12,16 \\
\hline Distância do local de trabalho & 11,34 & 2,81 & 4,72 & 15,00 \\
\hline Quantidade de equipamentos & 6,14 & 2,86 & 1,05 & 14,83 \\
\hline Conservação dos equipamentos & 5,13 & 2,33 & 0,79 & 11,94 \\
\hline Serviços de manutenção & 4,97 & 2,60 & 0,70 & 9,53 \\
\hline Material de almoxarifado & 6,46 & 2,90 & 1,35 & 10,71 \\
\hline Satisfação geral em relação ao ambiente físico & 5,72 & 2,89 & 0,09 & 11,00 \\
\hline
\end{tabular}

Ao abordar questões acerca das características e organização do trabalho observou-se, em quase todos os itens, em média, uma melhora na satisfação dos funcionários (Tabela 2 -). Exemplo disso é a satisfação quanto à autonomia no trabalho, que obteve média de 10,94. Como o salário foi um item de destaque positivo, pode-se esperar que este influencie outras questões, sendo considerado um ponto-forte em pesquisas de satisfação, no sentido de que, quanto maior o salário, maior a satisfação geral por parte dos funcionários. Outro ponto positivo é a satisfação com a segurança no emprego, que foi também um dos itens com maior média $(11,80)$. O grau de satisfação geral com as características, atividades e organização do trabalho é positivo, com média de 10,93 e desvio padrão 2,34 .

Os aspectos negativos ficaram por conta da segurança em relação ao futuro da PRF, já que é vulnerável a incertezas pela falta de critérios padronizados e determinações escritas; bem como da possibilidade de promoção (média 7,60), pois a função de Inspetor é obtida através de indicação. Também foram considerados insatisfatórios o reconhecimento do trabalho pela chefia (média 7,71) e as pausas durante o trabalho (média 8,37).

Foram realizadas quatro questões relacionadas aos objetivos do trabalho. Estas questões evidenciaram que os sujeitos consideraram o trabalho organizado (média 10,19) e com metas bem definidas (média 10,78). Os servidores também se sentem valorizados com o trabalho (média 11,91), acreditando que ele envolve grande responsabilidade, já que a média das respostas para esta questão foi a mais alta entre todos os itens avaliados $(13,61)$. 
Tabela 2 - Satisfação em relação às características e organização do trabalho

\begin{tabular}{l|c|c|c|c}
\hline \multicolumn{1}{c|}{ Item } & Média & $\begin{array}{c}\text { Desvio } \\
\text { Padrão }\end{array}$ & Mínimo & Máximo \\
\hline Satisfação por ser servidor público federal & 9,56 & 3,38 & 0,04 & 14,39 \\
\hline Satisfação por trabalhar na PRF & 11,76 & 2,56 & 0,00 & 15,00 \\
\hline Relacionamento com colegas e chefia & 11,33 & 1,85 & 7,08 & 14,17 \\
\hline Reconhecimento do trabalho pela chefia & 7,71 & 3,71 & 0,00 & 13,64 \\
\hline Quantidade de trabalho & 9,87 & 2,38 & 5,29 & 14,96 \\
\hline Autonomia no trabalho & 10,94 & 2,26 & 5,73 & 14,52 \\
\hline Motivação para o trabalho & 9,17 & 3,41 & 0,04 & 14,34 \\
\hline Segurança no emprego (estabilidade) & 11,80 & 2,18 & 4,78 & 15,00 \\
\hline Possibilidade de promoção & 7,60 & 3,40 & 0,00 & 14,61 \\
\hline Salário & 10,36 & 2,69 & 0,75 & 14,21 \\
\hline Segurança com relação ao futuro da PRF & 7,17 & 2,93 & 0,00 & 12,85 \\
\hline Qualidade do serviço da PRF & 9,27 & 2,98 & 0,00 & 14,47 \\
\hline Relacionamento com a população & 9,22 & 2,91 & 0,00 & 14,6 \\
\hline Possibilidade de auxiliar pessoas & 10,96 & 2,70 & 1,67 & 15,00 \\
\hline Variedade de tarefas a realizar & 11,21 & 2,52 & 3,77 & 15,00 \\
\hline Pausas durante o trabalho & 8,37 & 3,44 & 0,57 & 14,6 \\
\hline Satisfação geral com as atividades & 10,93 & 2,34 & 3,94 & 15,00 \\
\hline
\end{tabular}

O valor médio encontrado para o ICT foi de 43,24 com desvio padrão 4,37 e os valores mínimos e máximos observados foram 32 e 49, respectivamente. Essa média entra na classificação de ICT bom (Tabela 3 -), devendo ser aplicadas medidas para melhorá-la. Dentre os sujeitos pesquisados, um não respondeu todos os itens necessários ao cálculo do ICT. Desta forma, foi possível calcular sobre apenas 42 escores de índice.

Tabela 3 - Distribuição do ICT por classes

\begin{tabular}{l|c|c}
\hline \multicolumn{1}{c|}{ Classe de ICT } & N & \% \\
\hline Ótimo (44-49) & 23 & 54,8 \\
\hline Bom (37-43) & 15 & 35,7 \\
\hline Moderado (28-36) & 4 & 9,5 \\
\hline Baixo (7-27) & 0 & 0 \\
\hline Total & $\mathbf{4 2}$ & $\mathbf{1 0 0}$ \\
\hline
\end{tabular}

\subsection{Análise Bivariada}

Anterior à aplicação do ICT, foi realizada uma pesquisa acerca do número de Autos de Infração de cada policial, durante os cinco primeiros meses do ano de 2006, separando os indivíduos por tempo de serviço.

Os resultados mostrados na Figura 2 indicam uma queda importante de um dos indicadores de produtividade dos policiais com seis ou mais anos de serviço. A média de Autos de Infração (AIs) dos servidores com até 5 anos de serviço foi de 69,24 nos cinco primeiros meses de 2006. Já a média dos servidores com 6 anos ou mais de serviço foi de 44,73 AIs por policial, para o mesmo 
período. Essa expressiva queda de 35\% reflete indícios de envelhecimento funcional precoce, o qual pode ser avaliado pelo Índice de Capacidade para o Trabalho (ICT).

Figura 2 - Autos de Infração versus Tempo de Serviço

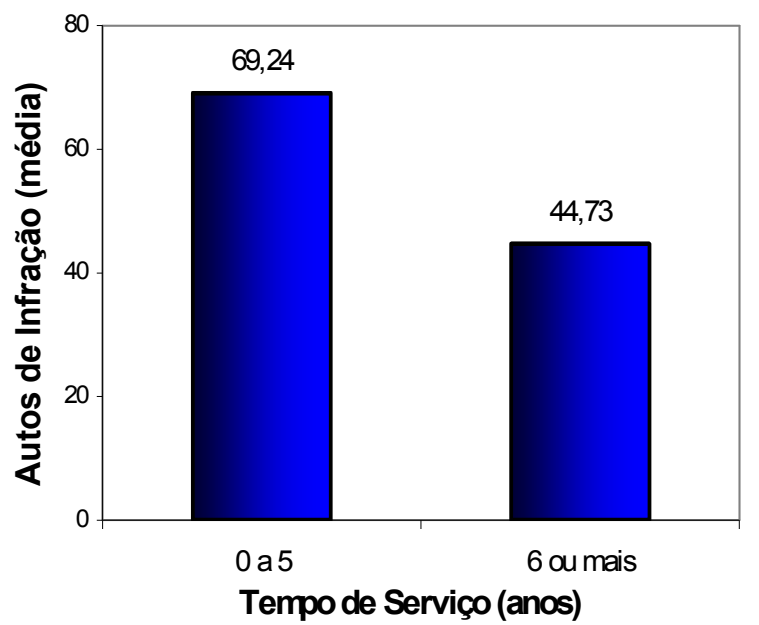

Os valores de ICT foram cruzados, primeiramente, com as variáveis demográficas para comparação de médias, conforme apresentado na Tabela 4 -. Foram significativas as diferenças entre os níveis de escolaridade ( $p$-value $=0,011$ ), sendo que indivíduos com curso superior tendem a ter um ICT maior que indivíduos com até o ensino médio completo. A análise dos resultados mostrou também que existe uma tendência de redução do índice à medida que aumenta da idade do indivíduo $(p$-value $=0,030)$. O mesmo pode ser verificado em relação ao tempo que o trabalhador permanece na organização ( $p$-value $=0,053)$.

Tabela 4 - Comparação do ICT médio por categorias

\begin{tabular}{|c|c|c|c|c|}
\hline Variável & Categoria & Média & Desvio Padrão & Teste de Médias \\
\hline \multirow{2}{*}{ Sexo } & Masculino & 43,40 & 4,14 & \multirow{2}{*}{$\begin{array}{c}\mathrm{t}=-0,510 \\
\text { p-value }=0,613\end{array}$} \\
\hline & Feminino & 44,70 & 2,52 & \\
\hline \multirow{3}{*}{ Estado Civil } & Solteiro & 45,50 & 2,41 & \multirow{3}{*}{$\begin{array}{c}\mathrm{F}=2,844 \\
p \text {-value }=0,071\end{array}$} \\
\hline & Casado / Companheiro & 42,40 & 4,59 & \\
\hline & Separado / Divorciado / Viúvo & 43,00 & 2,00 & \\
\hline \multirow{3}{*}{ Escolaridade } & Até Ensino Médio completo & 38,80 & 4,50 & \multirow{3}{*}{$\begin{array}{c}\mathrm{F}=5,077 \\
p \text {-value }=0,011\end{array}$} \\
\hline & Superior incompleto & 44,70 & 3,89 & \\
\hline & Superior completo / Pós-Graduação & 42,60 & 2,87 & \\
\hline \multirow{2}{*}{ Idade } & Até 30 anos & 44,80 & 3,02 & \multirow{2}{*}{$\begin{array}{c}\mathrm{t}=2,282 \\
\text { p-value }=0,030\end{array}$} \\
\hline & Mais de 30 anos & 42,00 & 4,59 & \\
\hline \multirow{2}{*}{ Tempo de Serviço } & Até 5 anos & 44,60 & 2,65 & \multirow{2}{*}{$\begin{array}{c}\mathrm{t}=2,068 \\
p \text {-value }=0,053\end{array}$} \\
\hline & Mais de 5 anos & 41,60 & 5,28 & \\
\hline
\end{tabular}

Algumas destas relações com o ICT também podem ser observadas na Tabela 5 - através do Coeficiente de Correlação de Pearson (r, variando de -1 a 1), bem como as associações do índice com as variáveis de satisfação. 
Tabela 5 - Correlação de variáveis de satisfação, idade e tempo de serviço com ICT

\begin{tabular}{l|c|c}
\hline \multicolumn{1}{c|}{ Variável } & Correlação (Pearson) & p-value \\
\hline Idade do funcionário & $-0,380^{*}$ & 0,014 \\
\hline Tempo de serviço na PRF & $-0,465^{*}$ & 0,003 \\
\hline Satisfação por trabalhar na PRF & $0,342^{*}$ & 0,029 \\
\hline Reconhecimento do trabalho pela chefia & $0,322^{*}$ & 0,040 \\
\hline Quantidade de trabalho & $0,410^{* *}$ & 0,008 \\
\hline Autonomia no trabalho & $0,494^{* *}$ & 0,001 \\
\hline Motivação para o trabalho & $0,396^{*}$ & 0,010 \\
\hline Possibilidade de promoção & $0,382^{*}$ & 0,014 \\
\hline Qualidade do serviço da PRF & $0,321^{*}$ & 0,041 \\
\hline Relacionamento com a população & $0,356^{*}$ & 0,023 \\
\hline Possibilidade de auxiliar pessoas & $0,473 * *$ & 0,002 \\
\hline Variedade de tarefas a realizar & $0,446 * *$ & 0,003 \\
\hline Satisfação geral com as atividades & $0,527 * *$ & 0,000 \\
\hline O trabalho envolve responsabilidade? & $0,322^{*}$ & 0,040 \\
\hline Faz você se sentir valorizado? & $0,492 * *$ & 0,001 \\
\hline Trabalho é organizado? & $0,311^{*}$ & 0,047 \\
\hline Correlação é significativa ao de nível de 5\% (teste t-student bicaudal) & \\
** Correlação é significativa ao de nível de 1\% (teste t-student bicaudal) & \\
\hline
\end{tabular}

Como já exposto na Tabela 4 -, as variáveis: idade do funcionário e o tempo de serviço são inversamente correlacionadas com o ICT, ou seja, quanto maior a idade do funcionário ou mais tempo na PRF, menor será seu índice. Variáveis como autonomia no trabalho, possibilidade de promoção, possibilidade de auxiliar pessoas, entre outras, têm correlação positiva e significativa ( $p$ value $<0,05)$ com o ICT, de forma que aumentando a satisfação com estes itens maior será o valor do Índice de Capacidade para o Trabalho. No entanto, é relevante considerar ainda o resultado da correlação com a satisfação em relação ao salário e o ICT, que não foi significativa e sendo praticamente nula $(\mathrm{r}=0,057 ; p$-value $=0,726)$. A ausência desta associação pode ser explicada pela política de salários da PRF, que comparada a outras profissões mantêm-se acima da média.

\subsection{Análise Multivariada}

Para tentar explicar o comportamento do ICT considerando conjuntamente os fatores estudados, utilizou-se o método de Regressão Linear Múltipla, tendo ICT como variável dependente. Os resultados obtidos são apresentados na Tabela 6 -.

Tabela 6 - Modelo de Regressão Linear Múltipla

\begin{tabular}{llccc}
\hline Variável & Descrição & $\beta$ & $p$-value & IC 95\% \\
\hline (Constant) & Intercepto & 37,096 & 0,000 & $(31,634 ; 42,557)$ \\
\hline AUTONOMI & Autonomia no trabalho & 0,495 & 0,058 & $(-0,018 ; 1,008)$ \\
\hline TEMPSERV & Tempo de serviço na PRF & $-0,337$ & 0,002 & $(-0,545 ;-0,129)$ \\
\hline PROMOCAO & Possibilidade de promoção & 0,362 & 0,032 & $(0,032 ; 0,692)$ \\
\hline
\end{tabular}

Assim, o modelo de regressão proposto para o ICT pode ser representado da seguinte forma: 


\section{$\mathrm{ICT}=37,096-0,337 *$ TEMPSERV $+0,495 *$ AUTONOMI $+0,362 *$ PROMOCAO}

Tal resultado indica que a cada ano de serviço na PRF reduziria o ICT em 0,337 unidades. No mesmo contexto, o acréscimo de uma unidade na escala de satisfação com a autonomia no trabalho aumentaria o ICT em 0,495 unidades; e ainda, o aumento de uma unidade na escala de satisfação com a possibilidade de promoção, acresceria 0,362 unidades ao ICT. O modelo encontrado é significativo ( $\mathrm{F}=9,899 ; p$-value $=0,000)$ com coeficiente de determinação $\left(\mathrm{r}^{2}\right)$ igual a 0,452 , mostrando que $45,2 \%$ da variabilidade total do ICT pode ser explicada pelos fatores tempo de serviço, satisfação com autonomia no trabalho e possibilidade de promoção.

\section{Conclusão}

Os resultados obtidos mostraram algumas questões geradoras de insatisfação para os policiais rodoviários federais. Dentre estas, as decorrentes da falta de recursos materiais e humanos, como as condições de área física e infra-estrutura dos postos, além das relacionadas à realidade de servidor público federal, como pouca possibilidade de promoção e segurança quanto ao futuro da Polícia Rodoviária Federal, mostraram-se as mais negativas na opinião dos servidores. Logo, é fundamental o conhecimento, por parte dos administradores dos recursos públicos, da importância das condições de trabalho para a manutenção da saúde da força de trabalho, estabelecendo medidas prioritárias de prevenção.

O envelhecimento da população é de fato uma das características da sociedade contemporânea, gerando desafios em todos os campos e exigindo a participação de todos. A inclusão social deve atingir todos os cidadãos, para que sejam garantidos os direitos de trabalho aos mais idosos, em igualdade de condições com os demais.

Como reflexão sobre ações que promovam o aumento do ICT, sugere-se a avaliação de diretrizes e mudanças na direção dos tópicos de satisfação com o trabalho com maior associação, expressos através do coeficiente de correlação de Pearson e pelo modelo de Regressão Linear Múltipla. De acordo com o modelo, a questão do tempo de serviço diminuir o valor do ICT e as questões relativas à satisfação com autonomia e promoção aumentarem o índice, apontam a importância de acompanhamento periódico das condições de trabalho. Assim, utilizar o ICT como um indicador para avaliar e acompanhar a capacidade funcional pode, portanto, permitir a identificação de possibilidades de intervenção e melhoria das condições de saúde e trabalho.

Deve-se atentar para o fato que o Índice de Capacidade para o Trabalho dos policiais deve ser melhorado, mesmo que consideravelmente bom. Porém, essas conclusões não devem ser 
estendidas a todos os grupos de policiais de forma indiscriminada, visto as particularidades de cada região do país e também a maneira com que cada situação deve ser tratada especificamente.

\begin{abstract}
Among the aspects more discussed concerning productivity and performance in organizations are workers' motivation and satisfaction. In this way, the understanding of work conditions becomes essential to prevent the workers' functional aging as well as their work ability. This paper aimes to analyze the work conditions of the Federal Highway Police in Porto Alegre and its metropolitan area by the factors that influence their work ability. The methodology was based on questionnaires to evaluate the satisfaction about work conditions and the Work Ability Index (WAI). This process afforded opportunity for a preliminary diagnosis about the subjects' work conditions. The findings indicated that autonomy, promotion possibilities and function time influence in the calculated index results.
\end{abstract}

Key-words: policeman, work ability index, functional aging.

\title{
Referências
}

BELLUSCI, S.M. Envelhecimento funcional e capacidade para o trabalho em servidores forenses. São Paulo: USP, 2002. Tese (Doutorado em Saúde Pública), Faculdade de Saúde Pública, Universidade de São Paulo, 2002.

BOLDORI, R. Aptidão física e sua relação com a capacidade de trabalho dos bombeiros militares do Estado de Santa Catarina. Florianópolis: UFRGS, 2002. Dissertação (Mestrado em Engenharia de Produção), Programa de PósGraduação em Engenharia de Produção, Universidade Federal de Santa Catarina, 2002.

DPRF. Departamento de Polícia Rodoviária Federal. Relatório da Gestão 2004 da 9a SRPRF/RS. Disponível em: $<$ http://www.dprf.gov.br>. Acesso em: 22 mai. 2006.

ILMARINEN, J. Aging and work. In: International Scientific Symposium in Aging and Work, Institute of Occupational Health, Helsinki, 1993.

ILMARINEN, J. Envelhecimento e trabalho. International Ergonomics Association Conference. Rio de Janeiro, outubro. 1995.

LEME, L. E. G. A gerontologia e o problema do envelhecimento. Visão histórica. In: PAPALÉO NETTO, M. (Org.). Gerontologia: a velhice e o envelhecimento em visão globalizada. São Paulo: Atheneu, p.13-25, 1996.

MARÍN, L.; IGUTI, A. M. Aposentadoria, Envelhecimento e Condições de Trabalho e Desemprego. Revista Brasileira de Saúde Ocupacional. v. 24, n. 89/90, 1997.

MARQUIÉ, J. C. Changements cognitifs, contraintes de travail et expérience: les marges de manoeuvre du travailleur vieillissant. In: MARQUIÉ, J. C.; PAUMÈS, D.; VOLKOFF, S. Le travail au fil de l'âge. Toulouse: Octares, 1995.

MARTINEZ, M. C. As relações entre a satisfação com aspectos psicossociais no trabalho e a saúde do trabalhador. São Paulo: USP, 2002. Dissertação (Mestrado em Saúde Pública), Departamento de Saúde Ambiental, Universidade de São Paulo. Faculdade de Saúde Pública, 2002.

MEIRELleS, M. A. E. Atividade Física na Terceira Idade: Uma abordagem sistêmica. Rio de Janeiro: Sprint, 1997. 
NAHAS, M. V. Atividade física, saúde e qualidade de vida: conceitos, estudos e sugestões para um estilo de vida ativo. Londrina. Midiograf, 2001.POHJONEN, T. Key components of work ability and how maintain them. Työterveiset, 1(Special Issue):4-5, 1991.

PASCHOAL, S. M. P. Epidemiologia do envelhecimento. In: PAPALÉO NETTO, M. (Org.). Gerontologia: a velhice e o envelhecimento em visão globalizada. São Paulo: Atheneu, 1996.

SANTOS, R. C. F. Política de manutenção de recursos humanos do DPRF: uma proposta de valorização do servidor. Monografia para a obtenção do título de Gerência Policial. Departamento de Polícia Rodoviária Federal. Brasília, 2004.

SILVA, G. M. Exposição Físico-Psicológica do Policial Rodoviário Federal no trabalho em turnos. Monografia para a obtenção do título de Gerência Policial. Departamento de Polícia Rodoviária Federal. Aquidauana, 2003.

SOUZA, A. K. G. Avaliação de Desempenho dos Policiais Rodoviários Federais: Contribuições para a Área Operacional. Monografia para a obtenção do título de Gerência Policial. Departamento de Polícia Rodoviária Federal. Brasília, 2003.

TUOMI, K.; ILMARINEN, J.; JAHKOLA, A.; KATAJARINNE, L.; TULKKI, A. Índice de capacidade para o trabalho. Institute of Occupational Health, Helsinki, traduzido por FISCHER, F. M. (Coord.) et al., FSPUSP, 19 p., 1997a.

TUOMI, K.; ILMARINEN, J.; MARTIKAINEN, R.; ALTO, L.; KLOCKARS, M. Aging, work, life-style and work ability among Finnish municipal workers in 1981-1992. Scandinavian Journal of Work, Environment \& Health, v.23, suppl. 1, p. 58-65, 1997 b.

ZENI, L. A. Z. R. A influência do envelhecimento e das condições de trabalho no comportamento alimentar e na capacidade de trabalho de trabalhadores idosos. Florianópolis: UFRGS, 2004. Tese (Doutorado em Engenharia de Produção), Programa de Pós-Graduação em Engenharia de Produção, Universidade Federal de Santa Catarina, 2004.

\section{Dados dos autores:}

Nome completo: Leonardo Tomazi Gaspary

Filiação institucional: Universidade Federal do Rio Grande do Sul, UFRGS

Departamento: Programa de Pós-Graduação em Engenharia de Produção

Função ou cargo ocupado: Engenheiro de Produção

Endereço completo para correspondência (bairro, cidade, estado, país e CEP): Av. Osvaldo Aranha, 99 - $5^{\circ}$ andar, CEP 90040-020, Porto Alegre, RS

Telefones para contato: (51) 33083491 - 33084292

e-mail: leonardogaspary@yahoo.com.br

Nome completo: Lisiane Priscila Roldão Selau

Filiação institucional: Universidade Federal do Rio Grande do Sul, UFRGS

Departamento: Programa de Pós-Graduação em Engenharia de Produção

Função ou cargo ocupado: MSc. em Engenharia de Produção

Endereço completo para correspondência (bairro, cidade, estado, país e CEP): Av. Osvaldo Aranha, 99 - $5^{\circ}$ andar, CEP 90040-020, Porto Alegre, RS 
Telefones para contato: (51) 33083491 - 33084292

e-mail: lisianeselau@producao.ufrgs.br

Nome completo: Fernando Gonçalves Amaral

Filiação institucional: Universidade Federal do Rio Grande do Sul, UFRGS

Departamento: Programa de Pós-Graduação em Engenharia de Produção

Função ou cargo ocupado: Professor Adjunto

Endereço completo para correspondência (bairro, cidade, estado, país e CEP): Av. Osvaldo Aranha, 99 - $5^{\circ}$ andar, CEP 90040-020, Porto Alegre, RS

Telefones para contato: (51) 33083491 - 33084292

e-mail: amaral@producao.ufrgs.br 